\title{
Heart morphology in wild and farmed Atlantic salmon Salmo salar and rainbow trout Oncorhynchus mykiss
}

\author{
Trygve T. Poppe ${ }^{1, *}$, Renate Johansen ${ }^{2}$, Gjermund Gunnes ${ }^{1}$, Brit Tørud ${ }^{3}$ \\ ${ }^{1}$ Norwegian School of Veterinary Science, Institute of Morphology, Genetics and Aquatic Biology, PO Box 8146 Dep., \\ 0033 Oslo, Norway \\ ${ }^{2}$ National Veterinary Institute, Fish Health Services, PO Box 8156 Dep., 0033 Oslo, Norway \\ ${ }^{3}$ Veterinary Service in Aquaculture, 6681 Valsøyfjord, Norway
}

\begin{abstract}
The normal shape of the salmonid ventricle is a triangular pyramid with the apex pointing caudoventrally. A strong positive correlation has been established between this shape and optimum cardiac output and function. Domesticated salmonids appear to have developed a more rounded ventricle with misaligned bulbus arteriosus. Several reports from fish health veterinarians indicate that fish with abnormal heart morphology have a high mortality rate during stress-inducing situations like grading, transportation and bath treatments. The present paper compares and describes the ventricle morphology of wild vs. farmed Atlantic salmon, and wild steelhead (anadromous rainbow trout) vs. farmed rainbow trout. Several parameters were measured to provide numerical measurement of the differences in shape, i.e. height:width ratio and the angle between the longitudinal ventricular axis and the axis of the bulbus arteriosus. We conclude that the hearts of farmed fish are rounder than those in corresponding wild fish, and that the angle between the ventricular axis and the axis of the bulbus arteriosus is more acute in wild fish than in their farmed counterparts. Further studies are necessary to reveal the prevalence, functional significance and possible causes of these abnormal hearts.
\end{abstract}

KEY WORDS: Heart morphology $\cdot$ Ventricular shape $\cdot$ Salmonids $\cdot$ Bulbus arteriosus $\cdot$ Salmo salar . Oncorhynchus mykiss

\section{INTRODUCTION}

Cardiac morphology and function in teleosts has been extensively studied using a wide range of methodologies, and a strong positive correlation has been established between morphology and function (Graham \& Farrell 1992, Agnisola \& Tota 1994, Franklin \& Axelsson 1994, Sanchez-Quintana et al. 1995, Sande \& Poppe 1995, Coucelo et al. 1996, Tota \& Gattuso 1996). Species occupying different habitats have different heart shapes that reflect the habitat and activity of the fish. For example, fish with sedentary habits like hake Merluccius merluccius and anglerfish Lophius piscatorius have tubular and saccular ventricles, respectively. Such hearts do mostly volume work (i.e. they move large stroke vol- umes at a low heart rate, while highly active and migrating fish like salmonids, scombrids and clupeids have pyramidal (triangular) hearts that are highly effective pumps (i.e. they move small volumes of blood at a relatively high rate under high pressure) (Agnisola \& Tota 1994, Sanchez-Quintana et al. 1995). Furthermore, these fish have a well-developed outer, compact myocardium with its own coronary blood supply, enabling these fish to travel long distances and jump high waterfalls (Farrell \& Jones 1992).

Heart morphology within one species may show great plasticity and may change during the life cycle as a response to environmental and physical demands. In rainbow trout Oncorhynchus mykiss, Graham \& Farrell (1992) have shown that the thickness of the outer 
compact myocardium varies with the 'lifestyle' and the environment of the fish. Anadromous rainbow trout have thicker outer myocardium than stationary, lakedwelling fish, and farmed fish have thinner outer myocardium than wild fish in the same environment. Furthermore, male fish had significantly larger hearts than female fish. The morphology of the ventricle may also change with increased workload on the heart, e.g. as a result of reduced oxygen availability in amoebic gill disease (AGD). Powell et al. (2002) reported that fish with histories of severe AGD had an overall thicker compact ventricular layer, and the length:width ratio was significantly higher than in fish with mild AGD.

Anomalies of the heart, particularly in farmed salmonids, have been associated with numerous 'conditions' in recent years. These include arteriosclerosis (Farrell 2002), anomalies in heart rate (Mercier et al. 2000), aplasia of septum transversum (Poppe et al. 1998), situs inversus of the heart (Kaada \& Hopp 1995), hypoplasia of the outer, compact ventricular myocardium (Poppe \& Taksdal 2000) and cardiac hernia with myocardial hypoplasia (Poppe et al. 2002). Common to all these abnormalities is restricted cardiac function, manifested by reduced tolerance to transportation, handling, grading and anaesthesia.

Numerous anecdotal reports from fish health veterinarians along the Norwegian coast indicate an emerging problem with seemingly healthy, well-fed fish that tolerate moderate handling like grading, netting, transportation and lice treatments poorly. Fish with small and abnormally shaped hearts are over represented in the mortalities after normal operational procedures. Bacteriological and virological tests are negative and there are few pathological findings other than congestion. Similar problems with abnormally shaped hearts have been described in farmed Atlantic salmon in British Columbia, Canada, by Brocklebank \& Raverty (2002), where up to $20 \%$ of the population died following pre-harvest grading, crowding and transportation. Aortic misalignment is believed to be the cause of similar problems in farmed brown trout Salmo trutta and rainbow trout in France (G. Claireaux pers. comm.).

While differences in ventricle mass and the relationship between the outer and inner ventricular myocardium in farmed fish has been thoroughly described (Graham \& Farrell 1992), little is known about ventricle morphology as a response to environmental influence and domestication. The aim of this study was to see whether ventricle morphology is significantly different in farmed vs. wild fish. We have looked closely at the ventricles of farmed Atlantic salmon Salmo salar and farmed rainbow trout Oncorhynchus mykiss and have compared them to those of corresponding fish from wild populations.

\section{MATERIALS AND METHODS}

Hearts from 4 different categories of fish were randomly sampled from presumably healthy fish: wild Atlantic salmon from 2 Norwegian rivers $(\mathrm{n}=46)$ (weight 0.5 to $6.4 \mathrm{~kg}$ ), farmed Atlantic salmon from 2 sea farms in Norway ( $\mathrm{n}=55$ ) (weight 3 to $5 \mathrm{~kg}$ ), anadromous rainbow trout (steelhead) from the Clearwater River, Idaho, USA ( $\mathrm{n}=50$ ) (weight 2 to $10 \mathrm{~kg}$ ) and seawater-farmed rainbow trout from Norway $(\mathrm{n}=52)$ (weight 3 to $5 \mathrm{~kg}$ ). After euthanasia the fish were measured and the heart, complete with atrium, ventricle and bulbus arteriosus, removed and fixed in $10 \%$ phosphate-buffered formalin.

All hearts were macroscopically observed and photographed from several angles. Several 2-dimensional measurements of lengths and angles were tested to give a good numerical method to describe the 3-dimensional differences in ventricle morphology. The height:width ratio of the caudal side of the ventricle and the alignment of bulbus arteriosus were selected as 2 satisfactory and simple numerical measurements to describe some of the heart morphology.

Height:width ratios. For measurements of the height:width ratio, all hearts were photographed with the cranio-ventral surface uppermost (Nikon Coolpix 995, Nikon). Images were analyzed using ImagePro 4.5 image analysis software (Media Cybernetics). A contour of the heart was cut out from the original image, drawing a line across the base to exclude the atrium and the bulbus arteriosus. The height of the ventricle was defined as the distance from the middle of the base to the apex, and the width was defined as the widest segment of the ventricle, parallel to the base (Fig. 1). The height and width of all ventricles were collated, and the height-to-width ratio calculated for each ventricle. Using the Student's $t$-test, the ratios from wild fish were compared with farmed fish for both species.

Alignment of bulbus arteriosus. For measurements of the angle between the longitudinal ventricular axis and the axis of the bulbus arteriosus, the hearts in lateral recumbency were photographed and analyzed as previously described. To define the longtitudinal axis of the ventricle, a steel needle was inserted between the atrioventricular orifice and the junction between the ventricle and the bulbus arteriosus, as shown in Fig. 2.

A line was drawn through the metal pin, corresponding to the longtitudinal axis of the heart. A second line was drawn through the middle of the bulbus arteriosus, proceeding distally until it crossed the longtitudinal axis. The image analysis software subsequently measured the angle $(\alpha)$ between the 2 lines (Fig. 2). 


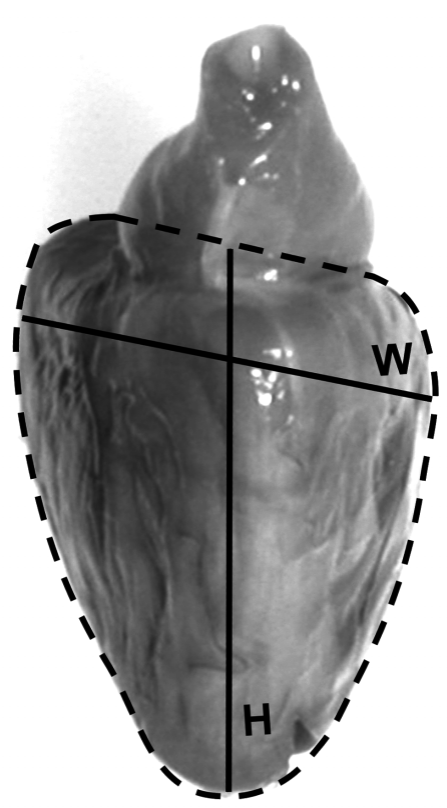

Fig. 1. Digital image of the ventricle cropped along the base of the heart to exclude the atrium and the bulbus arteriosus, as illustrated by the broken line. A straight line was drawn from the middle of the base to the apex and the length of this line, $\mathrm{H}$, was defined as the height of the ventricle. Another line was drawn across the widest segment of the ventricle parallel to the base. This line, $\mathrm{W}$, was defined as the width of the ventricle

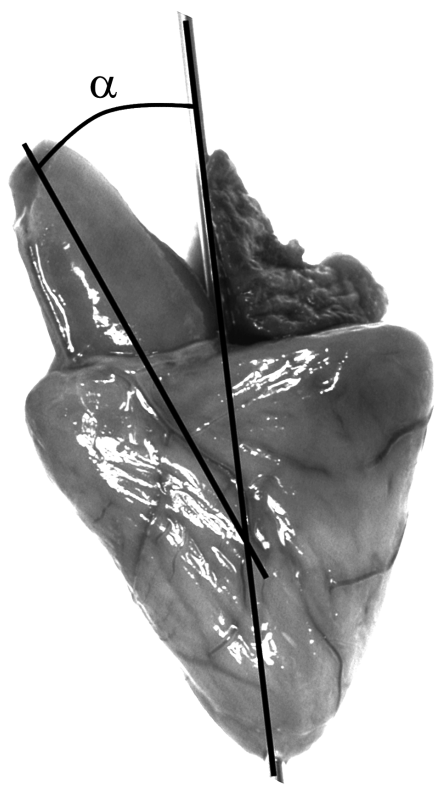

Fig. 2. A metal pin was inserted through the heart from the base to the apex. The hearts were photographed, and on the digital images, a line was drawn along the metal pin, corresponding to the long axis of the ventricle. A second line was drawn through the middle of the bulbus arteriosus, proceeding medially until it crossed the line of the longtitudinal axis. Image analysis software subsequently measured the angle $(\alpha)$ between the 2 lines
This angle was measured for wild $(\mathrm{n}=27)$ and farmed ( $\mathrm{n}=14$ ) rainbow trout and wild $(\mathrm{n}=26)$ and farmed ( $\mathrm{n}$ = 21) Atlantic salmon. Some hearts were used for histopathological studies (results not shown) and the number of hearts examined for alignment analysis therefore differs from the height:width ratio material. The data were analyzed in the JMP 4.0.2 statistical package (SAS Institute), and the rainbow trout groups and salmon groups were compared respectively, using the Student's $t$-test. The level of significance was set at 0.05 .

\section{RESULTS}

Macroscopical observations left no doubt that the hearts from both farmed Atlantic salmon and rainbow trout were significantly different from those of the corresponding wild fish.

Figs. $3 \& 4$ give a good impression of the ventricle shape differences between wild and farmed fish. When viewed both from the lateral and the ventrocranial side, the ventricles of both farmed Atlantic salmon and rainbow trout appear less pointed and triangular when compared to their wild counterparts. Furthermore, farmed fish frequently had conspicuous amounts of epicardial fat, as shown in Fig. 3c,d.

\section{Height:width ratios}

Height:width ratio data are given in Figs. $5 \& 6$. The ratio of each individual is designated by circles. The results for the Atlantic salmon groups are given in Fig. 5. The mean for wild fish was 1.15 and the mean for farmed fish was 1.05. The results for rainbow trout are given in Fig. 6. For the wild fish the mean was 1.31 and the mean for the farmed fish was 1.03. The Student's $t$-test showed that the means of the 2 groups of both species were significantly different ( $<<0.0001)$.

\section{Alignment of bulbus arteriosus}

These data are given in Figs. 7 \& 8. Each individual is designated by a circle. The results for Atlantic salmon are given in Fig. 7. The mean for the wild fish was 33.39, and the mean for the farmed fish was 40.23 . The Student's $t$-test showed that the means of the 2 groups were significantly different $(p=0.0005)$. The results for the rainbow trout are given in Fig. 8. For the wild fish the mean was 22.74 and the mean for the farmed fish was 28.57. The Student's $t$-test showed that the means of the 2 groups were significantly different $(\mathrm{p}=0.01)$. 

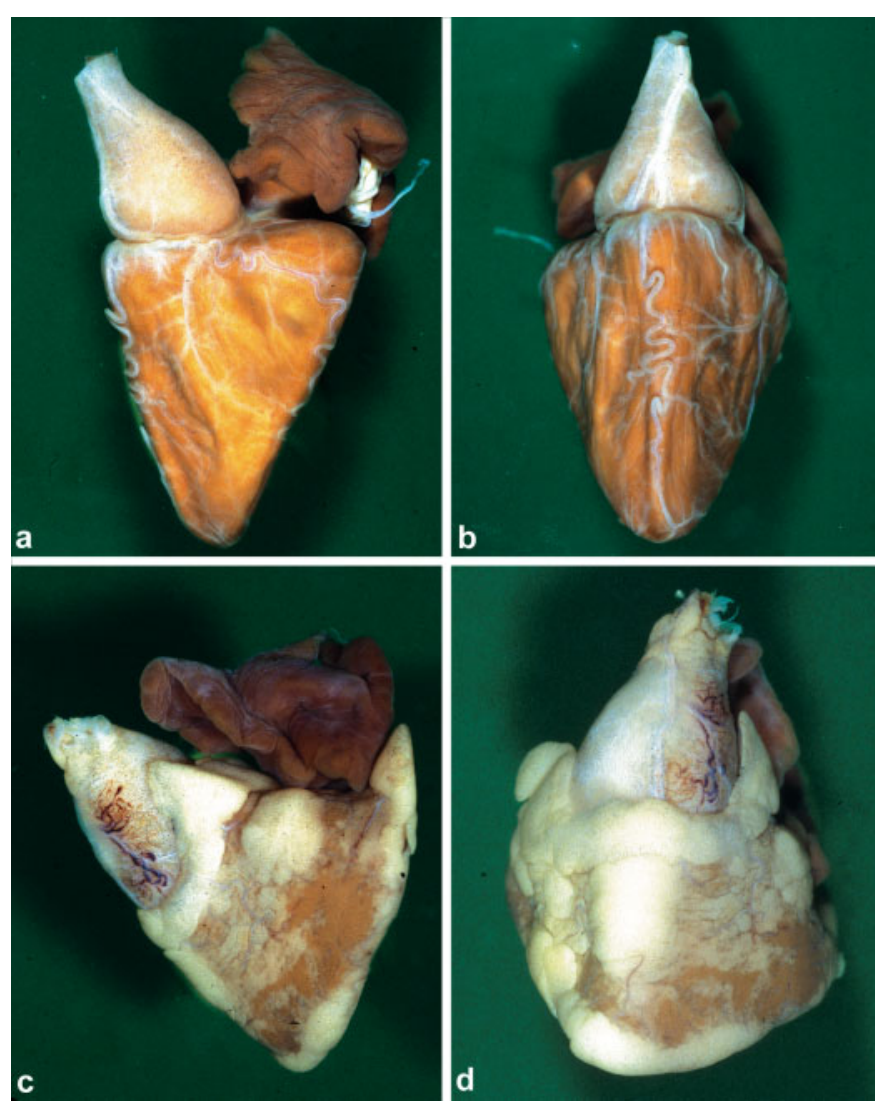

Fig. 3. Salmo salar. (a) Lateral and (b) cranio-ventral view of heart from wild fish. (c) Lateral and (d) cranioventral view of heart from farmed fish. Note the characteristic sharp triangular ventricle shape in the wild fish and the rounded ventricle in the farmed fish. There are conspicuous fat deposits in the epicardium of the farmed fish $(\mathrm{c}, \mathrm{d})$

the ratio of the object area to the area of a circle with the same perimeter as the object. This is a measure of an objects 'roundness' on a scale from 0 (straight line) to 1 (circle) (Dr. Alex C. Stan, Hannover, pers. comm.). It turned out, however, that differences easily observed by the naked eye were not readily demonstrated by the mathematical model. The most consistent results were obtained by using a simple height-to-width ratio, as described above.

Fish that succumb during crowding, grading and transportation are typically large fish in excellent condition, reflecting that their cardiac capacity has been sufficient for their relatively limited physical needs within the secluded environment of the cages. When these fish are exposed to physical challenges in excess of what they are 'designed' for, their limited cardiac capacity no longer can cope with the demands.

\section{DISCUSSION}

It appears, both from our own experience as well as reports from Canada and France (Mercier et al. 2000, Brocklebank \& Raverty 2002) that abnormally shaped hearts and misaligned vessels might be a widespread problem that has so far been overlooked in fish farming. The reduced cardiovascular capacity might cause severe losses due to increased mortality and reduced growth rate. There is also a major ethical dilemma involved in farming of fish that are unable to handle normal stress factors in the aquaculture operations.

The observation that the farmed fish hearts tended to have a rounder shape than the wild hearts initiated a search for a mathematical model that could describe a tendency of deviation from a triangular shape towards a round shape. In an early approach, a parameter was used that was defined as

Fig. 4. Oncorhynchus mykiss. (a) Lateral and (b) cranioventral view of heart from wild fish (steelhead). (c) Lateral and (d) cranio-ventral view of sea-farmed fish. Note characteristic sharp, triangular ventricle shape in the wild fish and the blunt, rounded ventricle appearance in the farmed fish
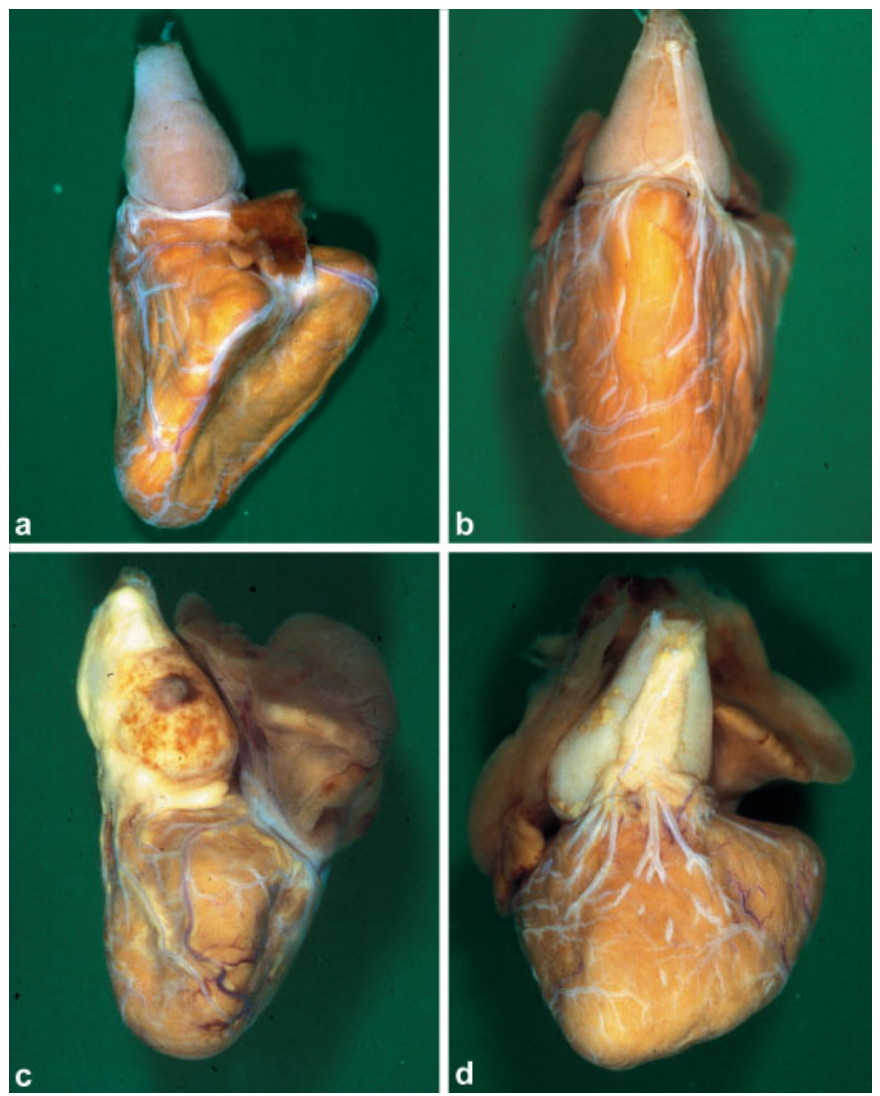


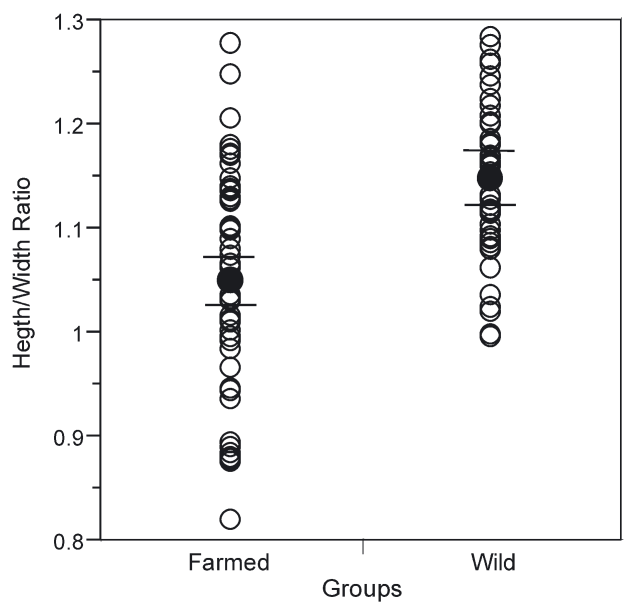

Fig. 5. Salmo salar. Scatter plots of ventricle height:width ratios in wild and farmed Atlanic salmon. Ratio of each individual (O); means (৩); $95 \%$ CI (-). Mean for wild fish is 1.15 and for farmed fish is 1.05 . Student's $t$-test showed that means of the 2 groups were significantly different $(\mathrm{p}<0.0001)$

Physical activity, in excess of that routinely experienced, requires a well-functioning heart. In addition to shape, this includes optimum (normal) angles between heart and vessels and coronary blood flow. As shape and function are intimately linked, the abnormally shaped heart of many farmed fish does not have the capacity to cope with energetically demanding situations or suboptimal rearing conditions (for example fouled nets, algal blooms/jellyfish, fast growth/increased oxygen demand, high temperature, no current between ebb and tide).

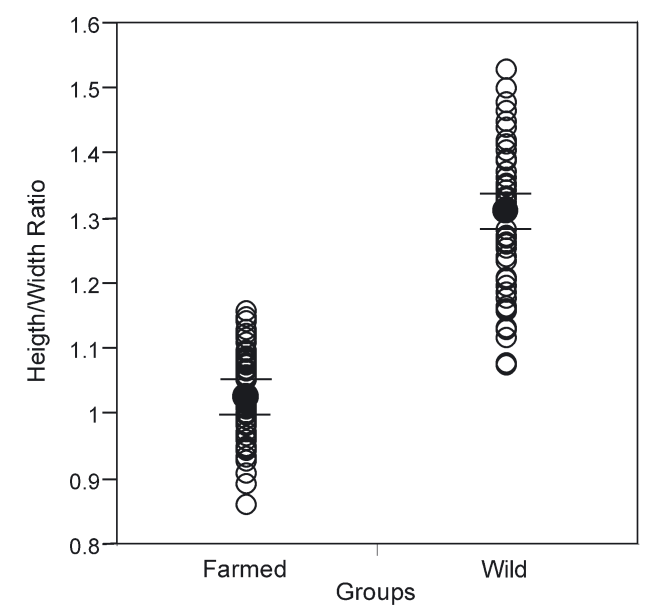

Fig. 6. Oncorhynchus mykiss. Scatter plots of ventricle height:width ratios in wild and farmed rainbow trout. Ratio of each individual (O); means (๑); $95 \%$ CI (-). Mean for wild fish is 1.31 and for farmed fish is 1.03. Student's $t$-test showed that means of the 2 groups were significantly different $(\mathrm{p}<0.0001)$

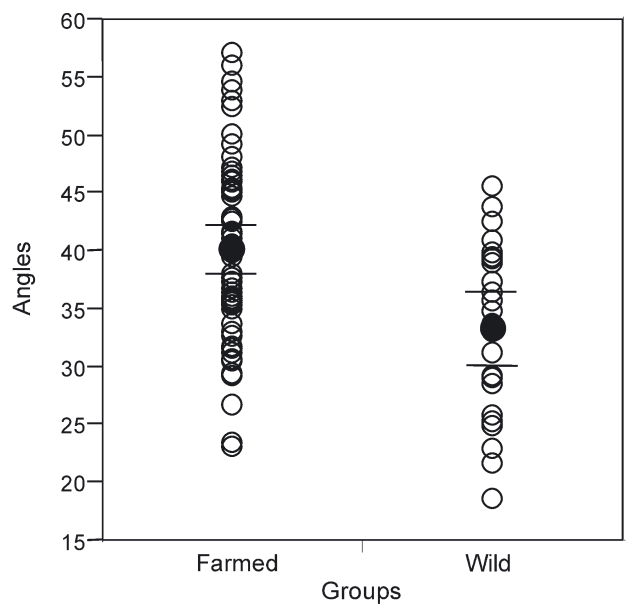

Fig. 7. Salmo salar. Scatter plots of angles between ventricular axis and bulbus arteriosus for wild and farmed Atlantic salmon. Angle of each individual (O); means (•); $95 \%$ CI (-). Mean for wild fish is 33.39 and for farmed fish is 40.23 . Student's $t$-test showed that means of the 2 groups were significantly different $(\mathrm{p}<0.0005)$

During periods of rapid growth, as in the fall months, the oxygen demand of the fish is at its maximum, while the levels of dissolved oxygen in seawater may be at their minimum. Fouling of the nets is a considerable problem in this period, and may result in impaired water exchange in the cages and even lower oxygen levels. In such periods with increased cardiovascular workload, maximum cardiac output is required and hearts with aberrant shape and function cannot fill the demands.

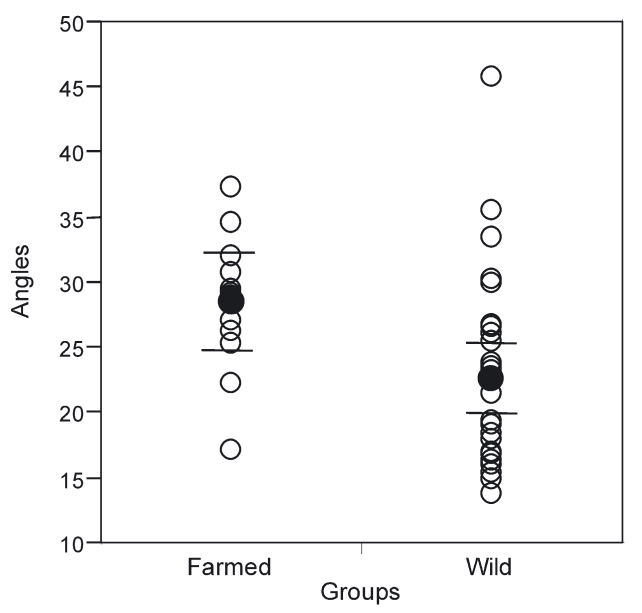

Fig. 8. Oncorhynchus mykiss. Scatter plots of angles between ventricular axis and bulbus arteriosus for wild and farmed rainbow trout. Angle of each individual (O); means (๑); $95 \%$ CI (-). Mean for wild fish is 22.74 and for farmed fish is 28.57. Student's $t$-test showed that means of the 2 groups were significantly different $(p=0.01)$ 
The rounded hearts in farmed fish could be the result of breeding, fast growth, a sedentary lifestyle, or a combination of all these factors. During the domestication process of salmonids, breeding programs have focused on rapid growth, flesh colour, late sexual maturation and, in recent years, resistance to infectious diseases. In this process, traits such as size, shape and function of organs may easily have been neglected. Graham \& Farrell (1992) have shown that the outer, compact myocardium is thicker in anadromous rainbow trout than in lake-dwelling populations, reflecting the different environmental requirements on the heart. Possible shape alterations are not addressed by these authors. The misalignment of the bulbus arteriosus appears to be a direct consequence of the altered heart shape and will further aggravate the overload of the heart and restrict the cardiac output during energydemanding situations.

Most of the steelhead from the Clearwater River are the result of hatchery enhancement, and this may also be the case for some of the Norwegian wild salmon. The hatchery enhancement programs exclude escapees from fish farms and have no breeding components and consequently no selection for traits such as rapid growth, body shape and late maturation, as is the case in the fish farming industry.

A possible factor with potential for further aggravation of the problem is arteriosclerosis. Arteriosclerotic lesions within the coronary vessels may occlude up to $50 \%$ of the vascular lumen and are therefore likely to represent a significant limit to normal performance (Farrell 2002). This condition is common in salmonids in seawater and particularly well developed in fastgrowing strains of fish. In Norway, it is beyond doubt that farmed fish are fast-growing, and the condition also occurs commonly in farmed salmonids (T. T. Poppe unpubl. data).

The present study confirms that there is a considerable difference in the heart morphology of farmed salmonids compared to wild fish. We believe that aberrant shape predisposes for cardiac failure during stressful situations such as grading, transportation and treatment. These fish are regularly exposed to stresses and environmental variables in excess of what their hearts are 'designed' for. Compromise or failure of the cardiovascular system will also impact a number of other systems, leading to suboptimal performance. Our findings indicate that more focus should be put on heart shape and function in farmed fish. Further research should concentrate on shape in response to different farming environments and breeding, the relationship between shape and function, shape and arteriosclerosis and size/shape in relation to body mass and feeding components. In addition to the obvious physical disadvantages of hearts with insufficient capacity, this productional disease also raises important ethical questions that should be properly addressed by the fish farming community.

Acknowledgements. We acknowledge Sverre Ludvig Seierstad for sampling hearts from farmed salmon and wild salmon from the river Namsen, Norway, Dr. Ron Sande, WSU, and representatives of US Fish and Wildlife Service, Idaho, for sampling steelhead hearts from the Clearwater River, Idaho, USA.

\section{LITERATURE CITED}

Agnisola C, Tota B (1994) Structure and function of the fish cardiac ventricle: flexibility and limitations. Cardioscience 5:145-153

Brocklebank J, Raverty S (2002) Sudden mortality caused by cardiac deformities following seining of preharvest farmed Atlantic salmon (Salmo salar) and by cardiomyopathy of postintraperitoneally vaccinated Atlantic salmon parr in British Columbia. Can Vet J 43:129-130

Coucelo J, Coucelo J, Azevedo J (1996) Ultrasonography characterization of heart morphology and blood flow of lower vertebrates. J Exp Zool 275:73-82

Farrell AP (2002) Coronary arteriosclerososis in salmon: growing old or growing fast? Comp Biochem Physiol A 132:723-735

Farrell AP, Jones DR (1992) The heart. In: Hoar WS, Randall DJ, Farrell AP (eds) Fish physiology, Vol. XIIA. Academic Press, San Diego, CA, p 1-88

Franklin CE, Axelsson M (1994) Coronary hemodynamics in elasmobranchs and teleosts. Cardioscience 5: 155-161

Graham MS, Farrell AP (1992) Environmental influences on cardiovascular variables in rainbow trout, Oncorhynchus mykiss (Walbaum). J Fish Biol 41:851-858

Kaada I, Hopp P (1995) Laks med deformerte hjerter og misdannede hjertesekker (Salmon with heart deformities and abnormal pericardial sacs). Bull Norw Vet Med Assoc 107:773-776 (in Norwegian) (English Abstract)

Mercier C, Aubin J, Lefrancois C, Claireaux G (2000) Cardiac disorders in farmed adult brown trout, Salmo trutta L. J Fish Dis 23:243-249

Poppe TT, Taksdal T (2000) Ventricular hypoplasia in farmed Atlantic salmon Salmo salar. Dis Aquat Org 42:35-40

Poppe TT, Midtlyng P, Sande RD (1998) Examination of abdominal organs and diagnosis of deficient septum transversum in Atlantic salmon, Salmo salar L., using diagnostic ultrasound imaging. J Fish Dis 21:67-72

Poppe TT, Johansen R, Tørud B (2002) Cardiac abnormality with associated hernia in farmed rainbow trout Oncorhynchus mykiss. Dis Aquat Org 50:153-155

Powell MD, Nowak BF, Adams MB (2002) Cardiac morphology in relation to amoebic gill disease history in Atlantic salmon, Salmo salar L. J Fish Dis 25:209-215

Sanchez-Quintana D, Garcia-Martinez V, Climent V, Hurle JM (1995) Morphological analysis of the fish heart ventricle: myocardial and connective tissue architecture in teleost species. Ann Anat 177:267-274

Sande RD, Poppe TT (1995) Diagnostic ultrasound examination and echocardiography in Atlantic salmon (Salmo salar). Vet Radiol Ultrastruct 36:551-558

Tota B, Gattuso A (1996) Heart ventricle pumps in teleosts and elasmobranches: a morphodynamic approach. J Exp Zool 275:162-171

Submitted: April 22, 2003; Accepted: June 16, 2003

Proofs received from author(s): October 30, 2003 